\title{
IMUNODIAGNÓSTICO DA ESQUISTOSSOMOSE MANSÔNICA COM BAIXA CARGA PARASITÁRIA
}

\author{
Dirce Mary C. Lima, Clarice P. Abrantes-Lemos, Sumie Hoshino-Shimizu, \\ Luiz P.C. Valli, Hermínia H.Y. Kanamura, Luiz Caetano da Silva \\ e Silvia A.G. Vellosa
}

\begin{abstract}
Atualmente, a esquistossomose mansônica com baixa carga parasitária é freqüente, e desta forma, ensaios imunológicos de interesse ao diagnóstico populacional de infecção leve por Schistosoma mansoni foram aqui avaliados. Incluiram-se neste estudo ensaios anteriormente não avaliados (grupo l) e pouco avaliados (grupo Il) para triagem de infeç̧ões leves. No grupo I, destacarain-se as reações de iununofluorescência destinadas à detecção de anticorpos $1 g M$ antiverme (RIFv IgM), e de anticorpos $\lg G$ anti-ovo (RIFo $\lg G$ ) por apresentarem niveis elevados de sensibilidade, especificidade, eficiencia e valor preditivo positivo. Todavia, os ensaios inunoenzimáticos para a detecção de anticorpos $\lg M$, antiverme (ELISAv IgM) e antiovo (ELISAo IgM) revelaram niveis menores que as reações acima. Os ensaios do grupo II, namaioria utilizada para detecção de anticorpos Ig G contra os mesmos antigenos, demonstraram desempenhos diagnósticos satisfatórios. Os dados aqui obtidos contribuíram para evidenciar pelo menos três categorias de ensaios imunológicos, e concluímos que os de categoria I são apropriados para estudos soroepidemiológicos de infeç̧ão leve por $\mathrm{S}$. mansoni, em vista de suas características diagnósticas permanecerem inalteradas mesmo que a intensidade de infeç̧ão por S. mansoni varie significativamente.
\end{abstract}

Palavras-chaves: Infecção leve. Sorodiagnóstico. Esquistossomosemansônica. Anticorpos $\lg M$ e $\lg G$.

A esquistossomose é endêmica em países tropicais e os dados fornecidos pela Organização Mundial de Saúde ${ }^{2}$ mostram que em localidades onde os programas de controle epidemiológico tiveram sucesso, a prevalência bem como a intensidade da infecção diminuíram consideravelmente, a par das formas graves da doença. Além disso, infecções leves são também encontradas nas áreas onde o vetor é Biomphalaria tenagophila, assim como, em pacientes após a quimioterapia ${ }^{10}$.

Em áreas de esquistossomose de baixa endemicidade, a falha diagnóstica tende a ocorrer freqüentemente, a não ser que exaustivos exames

Instiluto Adolfo Lutz, Instituto de Medicina Tropical de Sāo Paulo e Faculdade de Ciências Farmacêuticas da Universidade de São Paulo, São Paulo, SP.

Auxílio Financeiro: Fundação Nacional de Saúde/Ministério da Saúde, e parcialmente de Coordenaçāo de Aperfeiçoamento de Pessoal de Nível Superior, Fundaçāo de Amparo à Pesquisa do Estado de São Paulo e Laboratório de Investigaçāo Médica (LIM 06 e LIM 47) do HC/FMUSP.

Endereço para correspondência: Dra. Dirce Mary C. Lima. MTSP. Av. Dr. Eneas de Carvalho Aguiar $470,2^{\circ}$ andar, 05403-000 São Paulo, SP.

Recebido para publicação em 28/12/95. parasitológicos de fezes sejam efetuados ${ }^{9}$. Nestas circunstâncias, ensaios imunológicos prestam inestimável auxílio, complementando os dados parasitológicos ${ }^{2}$.

Vários ensaios imunológicos, baseados na detecção de anticorpos, foram propostos ${ }^{13} 16172022$ para o diagnóstico da esquistossomose mansônica, utilizando diferentes antígenos provenientes do ciclo evolutivo de Schistosoma mansoni. Até a última década, a maioria dos ensaios imunológicos estava adequada para a deteç̧ão de anticorpos IgG anti-S. mansoni.

Os estudos prévios ${ }^{17}$ mostraram que esses ensaios apresentavam características semelhantes quando avaliados em infecções com baixa, intermediária e alta carga parasitária.

Recentemente, avaliamos ${ }^{15}$ alguns ensaios imunológicos que detectam anticorpos IgM e IgG considerados marcadores diagnósticos tanto da infecção aguda como da crônica, fazendo o uso de antígenos de verme ou ovos do parasita. Os resultados demonstraram que a eficiência diagnóstica variava notadamente quando os ensaios eram aplicados em pacientes eliminando menos de 100 ovos por grama (OPG) de fezes. 
Lima DMC, Abrantes-Lemos CP, Hoshino-Shimizu S, Valli LPC, Kanamura HHY, Silva LC, Vellosa SAG. Imunodiagnóstico da esquistossomose mansônica com baixa carga parasitária. Revista da Sociedade Brasileira de Medicina Tropical 29:145-152, mar-abr, 1996.

Portanto, no presente trabalho, abordamos melhor este aspecto, estudando aqueles ensaios imunológicos ainda não avaliados ou pouco avaliados como por exemplo, o ensaio imunoenzimático, ELISA e de imunofluorescência para a deteç̧ão de anticorpos IgM e IgG, utilizando antígenos de vermes e ovos, em pacientes com infecções leves por S. mansoni.

\section{MATERIAL E MÉTODOS}

\section{Métodos parasitológicos}

Amostras de fezes foram coletadas de pacientes do ambulatório do Laboratório de Hepatologia do Instituto de Medicina Tropical de São Paulo (IMTSP) e de funcionários da Universidade de São Paulo (USP) e submetidas ao exame parasitológico quantitativo de Kato-Katz ${ }^{14}(\mathrm{MKK})$, realizado com 3 lâminas, assim como ao exame qualitativo de eclosão de miracídios (MEM) descrito anteriormente com algumas modificações como segue. A $30 \mathrm{~g}$ de fezes foram adicionados $200 \mathrm{ml}$ de água, e filtrados com gaze em um frasco cônico. Após manter o frasco ao abrigo da luz por 30 minutos, o sobrenadante foi desprezado, e o sedimento lavado com água a cada 10 minutos em ambiente sem luz, até o sobrenadante tornar-se claro. O sedimento foi então colocado em um frasco de fundo chato, adicionando-se água $\left(25^{\circ}\right.$ a $\left.28^{\circ} \mathrm{C}\right)$ para completar o volume de $50 \mathrm{ml}$ e deixando-se sob $\mathrm{a}$ incidência da luz. $\mathrm{O}$ aparecimento de miracídios na parte superior do frasco foi registrado, por visualização normal ou com uma lupa de aumento, a cada 15 minutos na primeira hora e depois a cada 60 minutos, nas 24 horas subseqüentes. Os resultados do MEM, embora fossem qualitativos, receberam arbitrariamente valores de $1+$ a $4+$, de acordo com o número de miracídios presentes. A intensidade da infecção por $S$. mansoni foi expressa em OPG de fezes, de acordo com o MKK.

\section{Casuística}

Um total de 39 pacientes com esquistossomose mansônica foi selecionado para o estudo, no IMTSP, com bases nos dados de exames parasitológicos.
Pacientes eliminando menos que 100 OPG fezes e aqueles negativos no $\mathrm{MKK}$, porém positivos no MEM foram também incluídos. Todos os pacientes eram migrantes procedentes de diferentes estados onde a esquistossomose é endêmica e que moravam na cidade de São Paulo por um período que variava de 2 meses a 28 anos. Este grupo de pacientes era constituído de homens e mulheres com 18 a 44 anos de idade. Clinicamente, apresentavam formas intestinais crônicas ${ }^{18}$, com exceção de uma paciente que tinha a forma hepatointestinal da doença. $O$ grupo controle consistiu de 44 funcionários da USP, considerados clinicamente sadios e que sempre viveram na cidade de São Paulo, consistindo também de homens e mulheres com idades de 18 a 52 anos, apresentando exames parasitológicos negativos para esquistossomose.

\section{Ensaios sorológicos}

Soros foram colhidos de pacientes esquistossomóticos e de indivíduos sadios e conservados a $-20^{\circ} \mathrm{C}$. A seguir, os pacientes com esquistossomose foram tratados.

$\mathrm{Na}$ reação de imunofluorescência, para a detecção de anticorpos IgM ou IgG (RIF-IgM e RIF-IgG), os antígenos empregados foram: vermes adultos e fígado infectado de hamster com granuloma hepático seccionados no criostato ${ }^{11}$, tendo os limiares de reatividade (LR) correspondente ao título 20, além de vermes adul tos emblocados em parafina ${ }^{5}$ e seccionados em micrótomo, com LR no título 10.

Os ensaios imunoenzimáticos, ELISA, foram também estudados para a detecção de anticorpos $\operatorname{IgM}$ e $\operatorname{IgG}^{23}$, tendo os limiares de reatividade correspondentes a 2 desvios padrões obtidos do grupo de soros de indivíduos clinicamente sadios, com o uso de antígeno solúvel de vermes adultos obtido conforme já descrito ${ }^{7}$, assim como antígeno solúvel de ovos ${ }^{3}$, sendo este último antígeno doado pela Organização Mundial de Saúde.

\section{Avaliação dos ensaios imunológicos}

As características diagnósticas dos ensaios foram estudadas em termos de sensibilidade, 
Lima DMC, Abrantes-Lemos CP, Hoshino-Shimizu S, Valli LPC, Kanamura HHY, Silva LC, Vellosa SAG. Imunodiagnóstico da esquistossomose mansônica com baixa carga parasitária. Revista da Sociedade Brasileira de Medicina Tropical 29:145-152, mar-abr, 1996.

especificidade, como também em valores preditivos de resultados positivo e negativo ${ }^{8}$. Intervalos de confiança foram determinados para cada um destes parâmetros diagnósticos ${ }^{21}$. Para o cálculo da média geométrica dos títulos de RIF, os títulos foram transformados em $\log _{2}{ }^{19}$.

\section{RESULTADOS}

No grupo de pacientes esquistossomóticos, 37 $(94,9 \%)$ das 39 amostras fecais coletadas apresentaram ovos de $S$. mansoni, em média 80 OPG de fezes, de acordo com o MKK. O maior número de ovos encontrado por lâmina foi de 120 OPG de fezes. As mesmas amostras de fezes apresentaram baixa positividade, $48,7 \%(19 / 39)$ no MEM, em intensidades graduadas de $1+\mathrm{e} 2+$. No entanto, as duas amostras negativas no MKK foram positivas no MEM $(1+)$.

No grupo controle, todas as amostras fecais (44) foram negativas para os dois métodos parasitológicos.

Os dados obtidos por técnicas sorológicas estão apresentados nas Figuras 1 e 2, com as RIFv $\operatorname{lgM}$ (verme), RIFo IgG (ovo), ELISAv IgM (verme) e ELISAo Ig̣M (ovo) constituindo o grupo de ensaios

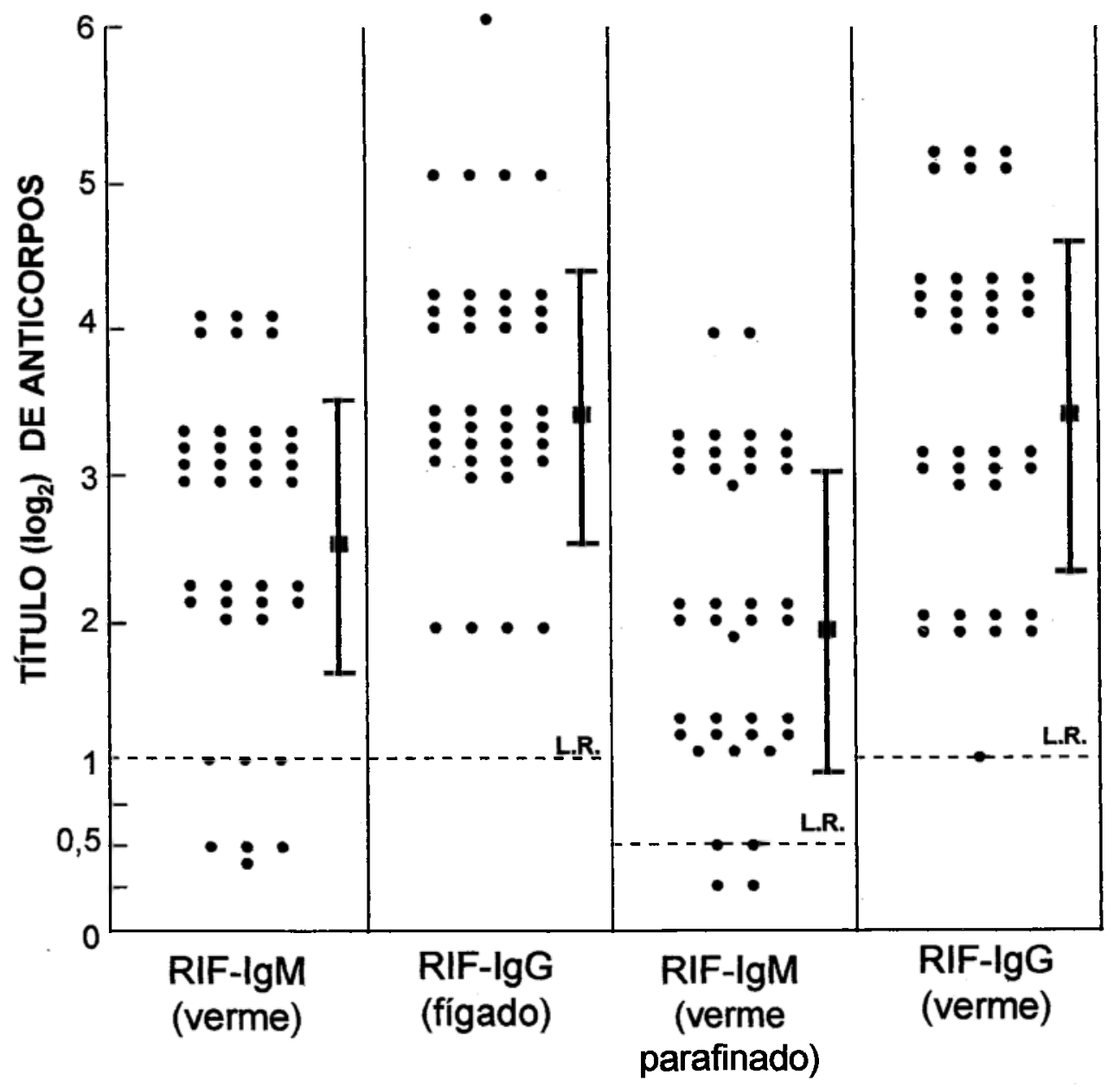

Figura 1 - Níveis de anticorpos contra vernes e ovos no granuloma hepático em títulos determinados por reaçâo de imunofluorescência, no estudo de 39 soros de pacientes com esquistossonose mansônica.

(|--1): Média geométrica dos titulos e desvio padrão.

LR: limite de reatividade. 
Lima DMC, Abrantes-Lemos CP, Hoshino-Shimizu S, Valli LPC, Kanamura HHY, Silva LC, Vellosa SAG. Imunodiagnóstico da esquistossomose mansônica com baixa carga parasitária. Revista da Sociedade Brasileira de Medicina Tropical 29:145-152, mar-abr, 1996.

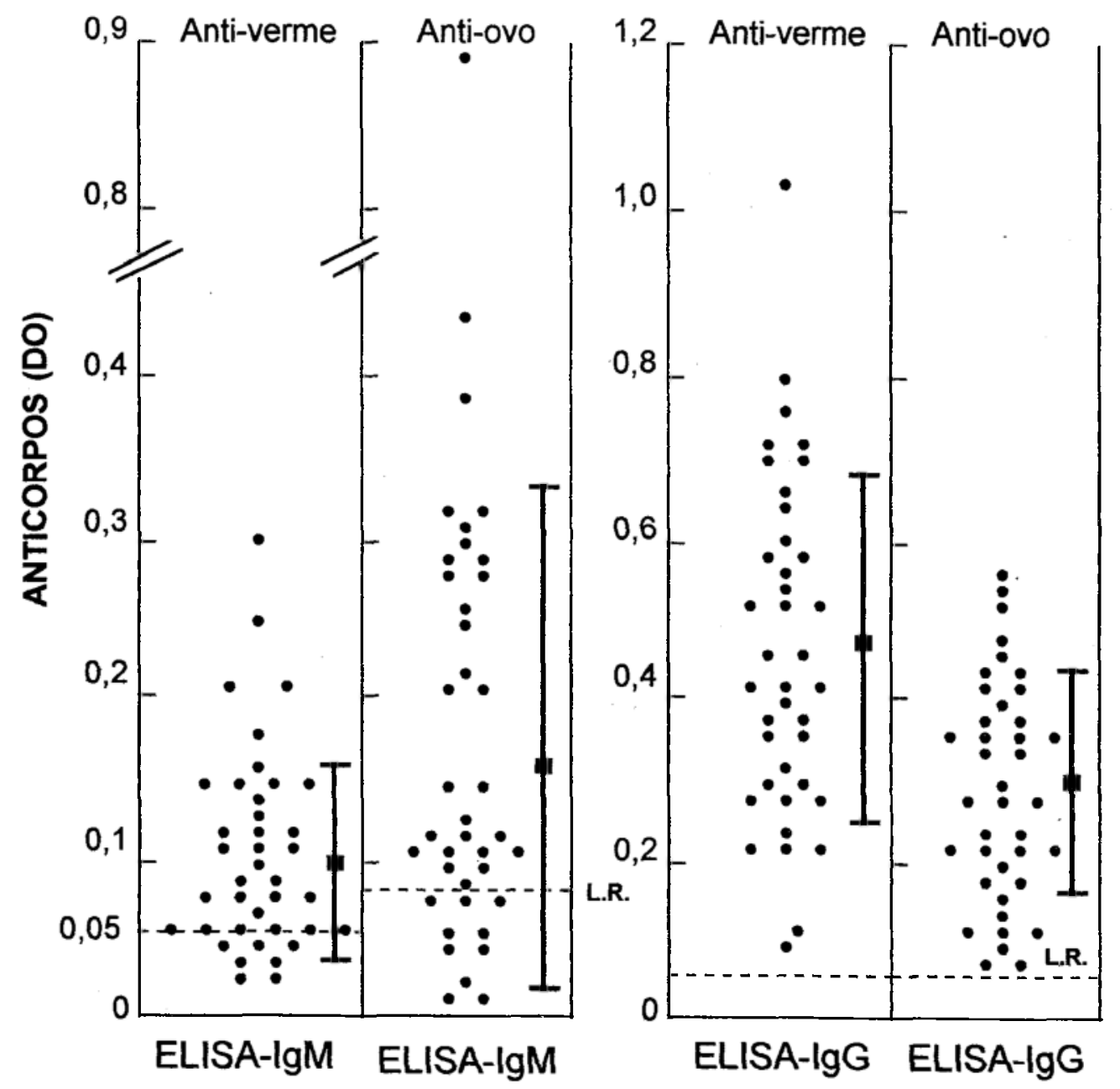

Figura 2 - Níveis de anticorpos $\operatorname{Ig} M$ e IgG, anti-verme e anti-ovo, eln densidade óptica (DO), determinados por ensaio imunoenzimático, ELISA, no estudo de 39 soros de pacientes com es quistossoinose mansônica.

(|--1): Média das densidades ópticas e desvio padrão.

LR: limite de reatividade.

ainda não avaliados em infecções baixas, enquanto os demais, os ensaios pouco avaliados. Na Figura 1 , anticorpos IgM contra vermes adultos foram encontrados em 35 dos 39 soros de pacientes esquistossomóticos por RIF, com títulos significativos variando de 20 a 160 , tendo a média geométrica dos títulos (MGT) de 2,6 em $\log _{2}$. Em 37 dos 39 soros estudados, anticorpos IgM contra o tubo digestivo de vermes parafinados foram detectados pela mesma reação, em títulos de 10 a 160, com MGT de 2,0. Os anticorpos IgG contra vermes adultos ou ovos nos granulomas hepáticos foram revelados em todos os soros pela RIF. Os títulos de anticorpos antiverme foram de 20 a 320 , sendo a MGT de 3,2; enquanto os anticorpos antiovo apresentaram títulos de 40 a 640 e MGT de 3,5.

$O$ ensaio imunoenzimático, ELISA, detectou anticorpos IgM antivermes e anti-ovos em níveis significativos (Figura 2), sendo os primeiros revelados em 32 dos 39 soros estudados e os últimos em 30 desses 39 soros. Os níveis significativos de anticorpos antivermes determinados em densidades ópticas (DO) variaram de 0,05 até 0,290 ; sendo a média da DO (MDO) de 0,097 . Os anticorpos antiovos apresentaram DO de 0,075 a 0,$895 ;$ e MDO de 0,178 . 
Lima DMC, Abrantes-Lemos CP, Hoshino-Shimizu S. Valli LPC, Kanamura HHY, Silva LC, Vellosa SAG. Imunodiagnóstico da esquistossomose mansônica con baixa carga parasitária. Revista da Sociedade Brasileira de Medicina Tropical 29:145-152, mar-abr, 1996.

Anticorpos IgG antivermes e anti-ovos foram demonstrados pelo mesmo ensaio acima, em todos os 39 soros de pacientes. As DO dos anticorpos IgG foram ligeiramente maiores que as dos anticorpos $\operatorname{IgM}$, sendo que para os antivermes variaram desde 0,092 a 1,114, correspondendo a MDO de 0,456. Paraos anticorpos anti-ovos, as DO tiveram variação de 0,057 a 0,548 , sendo a MDO de 0,276.

No grupo de indivíduos sadios, falsos resultados positivos foram encontrados em 7 dos 44 soros estudados, em ELISA-IgM, quando antígeno de vermes foi utilizado. No mesmo ensaio empregando antígeno de ovos, os resultados falsos positivos ocorreram em 13 soros. Nas demais técnicas, os soros foram todos negativos.

O desempenho diagnóstico das diferentes técnicas sorológicas está expresso em termos de sensibilidade, especificidade e em valores preditivos de resultados positivos e negativos (Tabela 1) sendo os ensaios do grupo I, correspondentes aos ainda não avaliados anteriormente em infecções leves e os do grupo II, aos pouco avaliados.

Os ensaios imunoenzimáticos, ELISA, foram reprodutíveis quando estudados contra 6 soros controles, sendo 3 positivos e 3 negativos pois, as determinações realizadas, em 6 diferentes dias, mostraram desvios padrões que variaram desde 0,002 a 0,180; não ultrapassando o limite estipulado de 0,200 .

As reações de imunofluorescência, nas mesmas condições de estudo acima, apresentaram, na sua maioria, concordância de títulos ou variação de título correspondente a uma diluição, considerada não significativa para os soros positivos controles. Resultados sempre negativos foram obtidos com os soros negativos controles.

\section{DISCUSSÃO}

Os dados do presente trabalho corroboram os nossos achados anteriores ${ }^{15}$, quanto à existência de ensaios imunológicos que modificam suas características diagnósticas ao serem aplicados em pacientes esquistossomóticos com baixa carga parasitária.

Desta forma, para avaliação de novos ensaios

Tabela 1 - Desempenho diagnóstico de diferentes ensaios imunológicos, no estudo de pacientes com esquistossomose mansônica tendo baixas cargas parasitárias.

\begin{tabular}{|c|c|c|c|c|c|}
\hline Ensaio & Antígeno & Sensibilidade & Especificidade & Eficiência & Preditivo de positivo \\
\hline \multicolumn{6}{|l|}{ Grupo $1^{a}$} \\
\hline RIF IgM & Verme & $\begin{array}{c}0,90 \\
(0,76-0,96)\end{array}$ & $\begin{array}{c}1,00 \\
(0,92-1,00)\end{array}$ & $\begin{array}{c}1,00 \\
(0,96-1,00)\end{array}$ & $\begin{array}{c}0,95 \\
(0,88-0,98)\end{array}$ \\
\hline RIF IgG & Ovo & $\begin{array}{c}1,00 \\
(0,91-1,00)\end{array}$ & $\begin{array}{c}1,00 \\
(0,92-1,00)\end{array}$ & $\begin{array}{c}1,00 \\
(0,96-1,00)\end{array}$ & $\begin{array}{c}1,00 \\
(0,91-1,00)\end{array}$ \\
\hline ELISA IgM & Verme & $\begin{array}{c}082 \\
(0,67-0,91)\end{array}$ & $\begin{array}{c}0,77 \\
(0,63-0,88)\end{array}$ & $\begin{array}{c}0,80 \\
(0,63-0,88)\end{array}$ & $\begin{array}{c}0,80 \\
(0,70-0,87)\end{array}$ \\
\hline $\begin{array}{l}\text { ELISA IgM } \\
\text { Grupo II }^{\text {b }}\end{array}$ & Ovo & $\begin{array}{c}077 \\
(0,62-0,87)\end{array}$ & $\begin{array}{c}0,68 \\
(0,52-0,80)\end{array}$ & $\begin{array}{c}0,72 \\
(0,61-0,81)\end{array}$ & $\begin{array}{c}0,70 \\
(0,55-0,81)\end{array}$ \\
\hline RIF IgM & $\begin{array}{c}\text { Verme } \\
\text { parafinado }\end{array}$ & $\begin{array}{c}0,95 \\
(0,83-0,99)\end{array}$ & $\begin{array}{c}1,00 \\
(0,92-1,00)\end{array}$ & $\begin{array}{c}0,98 \\
(0,92-0,99)\end{array}$ & $\begin{array}{c}1,00 \\
(0,91-1,00)\end{array}$ \\
\hline RIF IgG & Verme & $\begin{array}{c}1,00 \\
(0,91-1,00)\end{array}$ & $\begin{array}{c}1,00 \\
(0,92-1,00)\end{array}$ & $\begin{array}{c}1,00 \\
(0,96-1,00)\end{array}$ & $\begin{array}{c}1,00 \\
(0,91-1,00)\end{array}$ \\
\hline ELISA IgG & Verme & $\begin{array}{c}1,00 \\
(0,91-1,00)\end{array}$ & $\begin{array}{c}1,00 \\
(0,92-1,00)\end{array}$ & $\begin{array}{c}1,00 \\
(0,96-1,00)\end{array}$ & $\begin{array}{c}1,00 \\
(0,91-1,00)\end{array}$ \\
\hline ELISA IgG & Ovo & $\begin{array}{c}1,00 \\
(0,91-1,00)\end{array}$ & $\begin{array}{c}0,93 \\
(0,80-0,98)\end{array}$ & $\begin{array}{c}0,96 \\
(0,89-0,99)\end{array}$ & $\begin{array}{c}0,93 \\
(0,81-0,95)\end{array}$ \\
\hline
\end{tabular}

\footnotetext{
${ }^{a}$ Grupo I = ensaios avaliados pela primeira vez em infecção leve por $S$. mansoni;

${ }^{\mathrm{b}}$ Grupo II = ensaios pouco avaliados nas mesmas condições de infecção.
} 
Lima DMC, Abrantes-Lemos CP, Hoshino-Shimizu S, Valli LPC, Kanamura HHY, Silva LC, Vellosa SAG. lmunodiagnóstico da esquistossomose mansônica com baixa carga parasitária. Revista da Sociedade Brasileira de Medicina Tropical 29:145-152, mar-abr, 1996.

imunológicos, torna-se imprescindível a inclusão de soros de pacientes com infecção leve, no painel de soros de referência, por constituírem indicadores sensíveis para análise da eficiência diagnóstica.

Os resultados aqui obtidos revelam que ensaios empregando antígenos figurados, tanto de verme como de ovo do $S$. mansoni, como as reações de imunofluorescência apresentam alta eficiência diagnóstica, independentemente do isotipo de anticorpos detectado. Nos estudos anteriores ${ }^{111315}$, estas reações demonstraram ser eficientes tanto em infecções de cargas parasitárias moderadas como altas.

Os ensaios que utilizam antígenos solúveis de verme ou ovo, por sua vez, diferiram quanto à eficiência diagnóstica, sendo melhores aqueles destinados à deteç̧ão de anticorpos IgG que os de IgM. Ademais, os níveis de sensibilidade e especificidade que encontramos para ensaios imunoenzimáticos, ELISA, empregando antígeno de verme e ovo, foram mais elevados que os de outros autores ${ }^{17}$. Níveis moderados de eficiência diagnóstica foram observados para os ELISAv IgM e ELISAo $\operatorname{Ig} M$, mostrando a relevância de determinados epítopos que estão em quantidade suficiente nas RIFv IgM e RIFo IgM, e insuficiente naqueles imunoenzimáticos.

Os nossos dados, ainda preliminares, obtidos por técnica de "Western Blot", demonstram que anticorpos IgG de pacientes com infecção leve reconhecem as bandas antigênicas de vermes e ovos, correspondentes a $31 \mathrm{kDa}$ e $16 \mathrm{kDa}$, respectivamente. Desta forma, nos ensaios para os anticorpos $\mathrm{IgG}$, antígenos ricos em componentes associados a essas bandas antigênicas parecem conferi-los alta eficiência diagnóstica.

Os ensaios para a deteç̧ão de anticorpos IgM, por sua vez, exigem antígenos de natureza polissacarídica do que protéica ${ }^{511}$. Desta forma, pelo fato de extratos antigênicos solúveis conterem baixo teor de polissacárides, a sensibilidade diagnóstica dos ensaios imunoenzimáticos torna-se baixa.

A RIFvp IgM forneceu resultados ligeiramente mais sensíveis que a RIFv IgM. Uma das explicações seria o tratamento dos vermes com formaldeído antes de incluir em parafina, mantendo os antígenos polissacarídicos melhor preservados na estrutura do verme do que em vermes de cortes em criostato.

A sensibilidade da RIFvp IgM foi semelhante à encontrada por outros autores ${ }^{17}$, do mesmo modo que às observadas em infecções moderadas e altas ${ }^{5}$.

Os achados deste trabalho, em conjunto com os nossos dados anteriores ${ }^{15}$, permitem a evidenciação de pelo menos três categorias: I, II e III, de ensaios imunológicos com base na eficiência diagnóstica de infecção por $S$. mansoni de baixa carga parasitária ( $\leq 100$ OPG fezes).

Os ensaios de categoria I, abrangem os que apresentam alta eficiência diagnóstica independentemente da intensidade de infecção expressa em termos de oograma, como por exemplo, RIF IgG e IgM, e ELISA IgG. Os ensaios de categoria II, mostram moderada eficiência diagnóstica, porém, em infecções moderadas e altas têm alta eficiência diagnóstica, como exemplificados por ELISAr IgM e ELIEDA (Enzyme-linkedimmuno-electro-diffusion assay) $\operatorname{IgG}^{15}$. Os ensaios de categoria III, são aqueles de baixa eficiência diagnóstica e a eficiência torna-se moderada e alta, em paralelo a infecções de intensidade moderada e alta, respectivamente, como por exemplo, ELISAo IgM além de THAI (teste de hemaglutinação indireta), elEDA (immuno-electro-diffusion assay), estudados anteriormente ${ }^{15}$.

Os marcadores imunológicos apropriados para finalidades diagnósticas diferem daqueles para avaliação do tratamento de pacientes ${ }^{12}$, e os ensaios da categoria III, merecem melhores estudos, abordando a eficácia da quimioterapia.

O presente trabalho aponta a necessidade de efetuar escolha criteriosa dos ensaios imunológicos a fim de evitar a obtenção de dados inexatos nos estudos de campo.

Ensaios práticos assim como econômicos são de grande valia para inquéritos populacionais. Neste contexto, a RIFvp IgM apresenta características desejáveis, pois, os antígenos polissacarídicos $(\mathrm{CCA})^{5}$ conservam-se estáveis por longo período de tempo quando os vermes são incluídos em parafina. A par desta reação, os ensaios imunoenzimáticos, ELISA IgG, são também práticos por possibilitar a utilização de sangue colhido em papel filtro, como no caso da RIFvp IgM. 
Lima DMC, Abrantes-Lemos CP, Hoshino-Shimizu S, Valli LPC, Kanamura HHY, Silva LC, Vellosa SAG. Imunodiagnóstico da esquistossomose mansônica com baixa carga parasitária. Revista da Sociedade Brasileira de Medicina Tropical 29:145-152, mar-abr, 1996.

\section{SUMMARY}

Presently, the schistosomiasis mansoni with low worm burden is frequent, thus immunologic assays of interest for the field diagnosis of Schistosoma mansoni light infections were evaluated here. Assays not assessed before (group I) and those requiring better validation (group II) for the screening of light infections were included in this study. In the group $l$, the immunofluorescence assays for the detection of IgM antibodies to worm antigens $\left(\operatorname{Ig} M \quad I F A w^{\prime}\right)$ and $\lg G$ antibodies to egg antigens (IgG IFAe) gave high levels of sensitivity, specificity, efficiency and predictive value of positive. However, the immunoenzymatic assan's for the detection of IgM antibodies to worm antigens $\operatorname{lgM}$ ELISAw) and to egg anitigens (IgM ELISAe) had lower levels than the former assays. The assays from the group II designed inostly for the detection of $\mathrm{Ig} G$ antibodies $t o$ same parasite antigens showed good diagnostic performance. The data obtained here coniributed to evidenciate at least three category of immunoassays, and we concluded that those from the category l are suitable for seroepidemiologic purposes by keeping their diagnostic features unchanged even varying significantly the intensity of $\mathbf{S}$. mansoni infection.

Key-words: Light infection. Serodiagnosis. Schistosomiasis mansoni, $\lg M$ and $\lg G$ antibodies.

\section{AGRADECIMENTOS}

À Fundação Nacional de Saúde pelo auxílio financeiro, à Pesquisadora Científica Tokiko Kyomen Matsumoto por colaborar no preparo deste manuscrito e LIM 06 e LIM 47 do HC/FMUSP.

\section{REFERÊNCIAS BIBLIOGRÁFICAS}

1. Bergquist RN. Immunodiagnostic Approaches in Schistosomiasis. Ed. John Wiley \& Sons, New York, 1992.

2. Bergquist RN. Present Aspects of Immunodiagnosis of Schistosomiasis. Memórias do Instituto Oswaldo Cruz 87 (supl):29-38, 1992a.

3. Carter CE, Colley DG. An electrophoretic analysis of Schistosoma mansoni egg antigen preparation. Journal of Parasitology 64:385-390, 1978.

4. Chieffi PP, Siqueira JGV, Paschoaloni MA. Estudo sobre o método de eclosāo de miracídios para o diagnóstico da esquistossomose mansônica, em inquéritos epidemiológicos. Revista Brasileira de Malariologia a Doenças Tropicais 30:65-75, 1978.

5. Deelder AM. Kornelis D. A comparison of IFA and ELISA for the demonstration of antibodies against schistosone gut-associated polysaccharide antigens in schistosomiasis. Zeitschrift fur Parasitenkunde 64:65-75. 1980 .

6. Deelder AM, van Zeyl RJM. Fillié YE, Rolmans JP, Duchenne W. Recognition of gut-associated antigens by immunoglobulin $M$ in the indirect fluorescent antibody test for schistosomiasis mansoni. Transactions of the Royal Sociely of Tropical Medicine and Hygiene 83:364-367, 1989.

7. Feldmeir H. Buttner DW. Inmunodiagnosis of Schistosoma mansoni in man. Application of crude extracts from adult worm and cercariae in IHA and ELISA. Abl Bakl Hyg. Ab1, Orig A 255:413-421, 1983.

8. Galen RS. Gambino SR. Beyond Normality: the predictive value and efficiency of medical diagnosis. Ed. John Wiley \& Sons. New York, 1975.

9. Hoshino-Shimizu S. Camargo ME. Kawada HYK. Silva LC, Dias LCS. Aspeclos soroepidemiológicos da esquistossomose mansônica. In: Modernos Conhecimentos sobre Esquistossomose Mansônica. Anais da Academia Mineira de Medicina, 14(supl):67-89, 1986.

10. Hoshino-Shimizu S, Dias LCS. Kanamura HY, Silva LC, Glasser CM, Patueci RM. Seroepidemiology of schistosomiasis mansoni. Memórias do Instituto Oswaldo Cruz 87 (supl):303-306, 1992.

11. Kanamura HY, Hoshino-Shimizu S, Camargo ME, Silva LC. Class specific antibodies and fluorescent slaining patterns in acute and chronic forms of schislosomiasis mansoni. The American Journal of Tropical. Medicine and Hygiene 28:242-248, 1979.

12. Kanamura HY, Hoshino-Shimizu S, Lima DMC, AbrantesLemos CP. Silva LC. Schistosomiasis mansoni: Immunodiagnostic aspects and search for an immunologic marker related to terapeutic efficacy. Memórias do Instituto Oswaldo Cruz 82 (supl):217-218, 1987.

13. Kanamura HY, Hoshino-Shimizu S, Silva LC. Schistosoma mansoni cercaria and schistosomulum antigens in serodiagnosis of schistosomiasis. Bullelin of the Pan American Health Organization 26:220-229, 1992.

14. Kaz N, Chaves A, Pellegrino J. A simple device for quantitative stool thick smear technique in schistosomiasis mansoni. Revista do Instituto de Medicina Tropical de São Paulo 14:397-400, 1972.

15. Leal-Bacelar GM, Kanamura HY, Hoshino-Shimizu S, Lima DMC, Abrantes-Lemos CP, Silva LC. Evaluation of the enzyme-linked-immuno-electro-diffusion assay (ELIEDA) for the diagnosis of Schistosoma mansoni infection with low worm burden. Revista do Instiluto de Medicina Tropical de São Paulo 37:123-127, 1995.

16. Maddison SE. Serodiagnosis of parasitic diseases Clinical Microhiology Review 4: 457-469, 1991 .

17. Mott KE, Dixon H. Collaborative study on antigens for immunodiagnosis of schistosomiasis. Bullelin of the World Health Organization 60:729-753, 1982. 
Lima DMC, Abrantes-Lemos CP, Hoshino-Shimizu S, Valli LPC, Kanamura HHY, Silva LC, Vellosa SAG. Imunodiagnóstico da esquistossomose mansônica com baixa carga parasitária. Revista da Sociedade Brasileira de Medicina Tropical 29:145-152, mar-abr, 1996.

18. Neves J. Quadro clínico. In: Cunha AS (ed) Esquistossomose mansoni. São Paulo, Savier e Editora da Universidade de São Paulo p. 131-191, 1970.

19. Paul SR, White C. Serological Epidemiology. Ed Academic Press, New York, 1973.

20. Rabello ALT, Garcia MM, Dias Neto E, Katz N. Dot-dyeimmunoassay and dot-ELISA for the serological differentiation of acute and chronic schistosomiasis mansoni using keyhole limpet haemocyanin as antigen. Transactions of the Royal Society of Tropical Medicine and Hygiene 87:279-281, 1993.

21. Rothman KJ, Boice JD. Epidemiologic Analysis with
Programmable Calculator. Epidemiology Resouces Inc, Boston, 1982.

22. Silva AJ, Piuvezan MR, Moura H, Maddison S, Peralta JM. Rapid competitive enzyme-linked immunosorbent assay using a monoclonal antibody reactivity with 15 Kilodalton tegumental antigen of Schistosoma mansoni for serodiagnosis of schistosomiasis. Journal of Clinical Microbiology 31:2315-2319, 1993.

23. World Health Organization. The enzyme-linked immunosorbent assay (ELISA). Bulletin of the World Health Organization 54:129-139, 1976. 